DISEASES OF THE BLOOD_By Paul W. Clough, M.D. London: A. \& C. Black, Ltd. 1930. Pp. $\checkmark$ plus 310 . Illustrated. Price, 6s. net.

Diseases of the blood are of particular interest to medical men practising in the tropies. Dr. Clough's monograph should, therefore, appeal to a wide circle of readers who require a somewhat more detailed account than is given in the ordinary textbooks of medicine. The opening chapters are devoted to the origin, morphology and functions of the red and white cells. These cells are fully described and some excellent coloured plates of normal and pathological bloods are provided. Then follows a classification of the anæmias, after which the various types are described in detail. The chapter on pernicious anæmia is particularly good. Dr. Clough points out that the significance of the megaloblast in the diagnosis of this condition depends largely on how the term megaloblast is interpreted. There is great tendency to classify as a megaloblast any large red cell with a nucleus that is not pycnotic. Such cells are not uncommon in many other anæmias. The term should be restricted, as pointed out by Naegli, to those cells which have a nucleus about the size of a normal red cell and in which the nucleus shows a well defined fine chromatin network.

Piney's views that pernicious anæmia can only occur in such persons as have a remnant of megaloblastis tissue in their livers receive full consideration. The author holds that while such constitutional defect may predispose to the disease, it does not provide an adequate explanation of many of the manifestations of the disease.

The sickle cell anæmia of the negro is described, also splenic anæmia and Von Jaksch's anæmia. There is a description of acholuric familial jaundice under the heading of hæmolytic jaundice. Next the author deals with the leucæmias and the hæmorrhagic diseases. Finally there are excellent chapters on blood transfusion and on the technique of blood examinations. Altogether a useful, clear and concise account of the blood diseases. The volume is a handy pocket size, the print is large and clear, and the binding good.

\section{J. D. S.}

ANGINA PECTORIS.-By Harlow Brooks, M.D. London: A. \& C. Black, Ltd. 1930. Pp. VIII plus 164. Price, 6s. net.

Angina pectoris has perhaps been the subject of more investigation than any other cardiac symptom. It was first described by Heberden in 1768 . Later Jenner and Parry associated it with disease of the coronary arteries. In our own time Clifford Allbutt, Mackenzie and Danielopolo have advanced explanatory theories. This 'breast pain' has come to signify a clinical entity of deadly significance. Clifford Allbutt sought to explain the pain by inflammatory areas and irritated nerve endings in the aorta. Mackenzie thought it was due to exhaustion of the heart muscle. Danielopolo attributes angina to inadequacy of the coronary circulation causing myocardial exhaustion. He recognises as predisposing factors inflammatory and atheromatous lesions obstructing the mouths and the courses of the vessels, also abnormal vaso-constrictor reflexes and a hyperexcitable condition of the sympathetic and visceral nervous system. Determining factors would be increased work of the heart or deficiency in the blood supply, possibly an muscle. The pain probably arises in the heart and most likely in the left ventricle. This would explain the tendency towards radiation to the left.

Dr. Harlow Brooks has written a small and eminently readable book on this engrossing subject. The first chapter is historical and pays tribute to the epoch making contributions of Heberden. Jenner and Lauder Brunton. Then follows a general description of the disease and its symptoms. The pathology of the condition is next discussed. The author considers this is varied but is definite enough to subclassify as due to:-

1. Disease or spasm of the coronary arteries.

2. Aortitis.

3. Myocarditis
Some or all of these may be present. They do not always cause symptoms but they always cause the menace of sudden death.

A chapter is devoted to pseudo-angina and the author discusses the differential diagnosis. English writers strongly discourage the use of this term and like ones, such as angina minor and secondary angina, as they confuse the issue and obscure the essential decision as to whether the patient has angina pectoris or not. Treatment occupies almost half the book. The author looks upon angina as a family disease and strongly stresses the importance of prophylactic treatment in the younger members of such families as are afflicted. Chapters are devoted to specific treatment and the treatment of the attack. Last of all surgical treatment is described. In this connection the work of Spiegel, Cutler and Jonnesco is discussed. The aim of all these is the division of the sensory paths from the heart or aorta. As such paths are very uncertainly known, the procedure can hardly be justified, except in cases of persistent and excessive attacks that have failed to react to any medical treatment. The method of Danielopolo of anæsthetising the dorsal nerve roots corresponding to the area of pain is not mentioned, although some surgeons have had complete success with this less severe operation. The book is an excellent monograph on an important subject and can be strongly recommended to those interested in the subject.

$$
\text { J. D. S. }
$$

LEPROSY: DIAGNOSIS, TREATMENT AND PREVENTION. - By Dr. E. Muir, M.D., F.R.C.S. (Ed.), 73 Pp. with 25 illustrations. Fifth Editlon. Published by the British Empire Leprosy Relief Association. 1930. Price, As. 8 only.

THis useful little handbook will probably be known to most of our readers. It details briefly and succinctly the essential knowledge with regard to leprosy which the general practitioner should possess, and short of a special training in the diagnosis and treatment of the disease, it is the best tuition that the doctor could have in the subject. It also deals briefly with the disease from the public health point of view.

In the present edition recent advances in knowledge have been incorporated. The preparation of hydnocarpus esters by the hot and cold process has been detailed in an appendix, as the author has found that many in charge of leper institutions require this information. The question of predisposing causes and secondary infections is considered more fully than before. The erythrocyte sedimentation test, which is proving so useful in determining the degree of resistance to the disease, is fully described. The lines along which a campaign should be carried on against leprosy are further elaborated in the light of evidence collected from various workers in India.

Whilst the book is written primarily for practitioners in India, its scope should certainly be very much wider. As a medical primer in leprosy, so to speak, it is of value to every medical man in India, whilst the authoritative position of its author emphasises its importance.

\section{THE PRACTICAL MEDICINE SERIES. SERIES 1929. GENERAL SURGERY. EDITED.-By E. A. 1929. GENERAL.D. Professor of Surgery, Wash- Graham, A.B., M.D., School of Medicine. Pp. 800 ington University School of . Chicago: The Year Book Publishers. Price, $\$ 3.00$.}

The Practical Medicine Series consists of a series of eight volumes published annually, covering the previous year's surgery, each volume being complete on the subject with which it treats for the year prior to its date of publication. The present volume is complete, satisfactory, and presents the advances made in surgery during 1929 in a small compass, well illustrated; it is therefore a.volume which every surgeon should possess.

The editor draws attention to some of the most important events in surgery in 1929. One of these is the extensive review by Harvey Cushing of 547 operations conducted in two years on brain tumours removed 